\title{
Research and practice on teaching reform in course design of analog electronic technology
}

\author{
Heng Wang ${ }^{1, \text { a }}$, Quanxin Zheng ${ }^{2}$ \\ ${ }^{1,2}$ School of Electronics and Information Engineering, Jingchu University of Technology, Jingmen 448000, \\ China \\ a wanghengwh@126.com
}

Keywords: course design; analog electronics; teaching reform

\begin{abstract}
Analog electronic technology course design is the important practical link of "analog electronic technology" course. It plays the irreplaceable role in the realization of professional training goal for automation, mechanical and electrical integration. Through the implementation of the course design, it causes the student to deepen the understanding of basic theoretical knowledge, mastering the technical key points, cultivating the operational ability, designing the thinking ability and innovative ability. Based on the above understanding, it is imperative to improve the teaching quality of analog electronic technology course design. Analog electronic technology course design teaching reform work is steady progressing in a planned and targeted way. After years of efforts and achieved certain results. The main experience of the reform is: we should increase the teaching hours of analog electronic technology course design, increase the investment of the experimental equipment; reform the teaching content and teaching methods; establish a scoring mechanism which suitable for curriculum design.
\end{abstract}

\section{Introduction}

Engineering in our country have different comments on the current engineering graduates' innovative spirit and practice ability, but criticism is in the majority. Such as their basic knowledge of engineering and technical knowledge is too narrow. And they are not familiar with the project environment, know superficial about our professional product design and the manufacture process; The understanding of some engineering problems is limited to the teachers, the textbook, and lack of their own ideas, lack of the innovative consciousness; They are not good at learning on the job and learning from practice; Their basic skills is poor, and so on. Many of opinions is pertinent and right. From the perspective of education, the growth of a high quality engineering talent is only related to the students' individual subjective active factor, school education factors also play an important part in individual growth and development, especially the professional basic course and specialized course teachers should response to social needs to reform and update the course constantly.

Analog electronic technology course design is the practice link after the "analog electronic technology" course, it plays an important role in promoting the theoretical knowledge transformed to practical ability. So how to inspire the students' innovative consciousness in the link, to cultivate the students' practical ability, so that students can master the basic theory of knowledge through the process of the simulated electronic system analysis and design, and master new technology, new methods of electronic design automation, it is a subject worth exploring. Based on this understanding, the author of analog electronic technology course design of teaching reform, has carried on the preliminary exploration.

\section{Increasing the investment and the teaching hours of course design}

It must meet two necessary conditions to make the analog electronic technology course design to achieve the established goals. 
1) Increase the teaching hours. The existing analog electronic technology course design teaching hours is a week, a total of 30 hours. After implementation, the result is that students can only design, installation and debugging one of the most basic unit circuit under the guidance of teachers. It limited to make the students have preliminary understanding to the unit circuit design and production, and to strengthen the link of applied and comprehensive training students' ability to apply knowledge, and to mobilize students' subjective initiative and creativity of ineffective. In order to improve the status of the practice, we must effectively strengthen the engineering quality of students and the cultivation of practice ability, we see this link of teaching time to two weeks, a total of 60 class hours. Thus, it ensures the implementation of the new content from time, and help to achieve the desired design analog electronic technology course teaching goal.

2) Increase the investment of the instrument and equipment in the analog electronic technology course design practice. Good learning environment and conditions is the lubricant of intellectual activity, is the study of dynamics and catalyst, it can make students away from passive infusion, accept knowledge and information, and leave from dependence to independence. Thus model electronic technology curriculum design will need to increase the reform of experimental electronic instrument and the equipment investment, to improve the curriculum design of the environment and conditions, and drag Electronic Workbench, Protel, EDA and other advanced methods and technology into the teaching of the course design. To do this, we should add a lot of common electronic instruments and equipment with good performance, purchase a large number of computer to meet the requirements of EDA in the design of analog electronic technology course, and build an ideal experiment to cultivate the students' engineering design ability and the ability.

\section{The teaching content and method of reform in analog electronic technology course design}

Our guiding ideology for analog electronic technology course design reform is: design content must be based on the basic theory of this course, and guarantee the basic of course design; at the same time, the current electronic technology new ideas, new techniques, new methods, reflects the advanced nature of the course design must be joined, pay attention to in the whole design process from the view of practical engineering to think problems, analyzing problems, reflect the course design, the practical application. Based on the above ideas, we change the original "analog electronic technology course design, course content a lot. We changes these most fundamental and most typical unit circuit design to the system for small electronic circuit design and adjustment. Such as audio amplifier design task contains field effect tube source extreme output device, RC active filter, and the basic application circuit of integrated operational amplifier circuit; Function signal generator design task by differential amplifier circuit, voltage comparing circuit and integral circuit,.......These topics deepen and expand the basic circuit theory teaching, it has comprehensive and applicability. It can also arouse interest of the students to the further theoretical study and the analog electronic technology "course design.

For the teaching method reform, the key is to properly handle the teachers' leading role and students' main body status of the relationship. We must change the past series die, teach the practice of finely, teachers should focus on boot, be persuasive, and cannot depend on thought, make students have to fully reflect the students' subject status, sufficient free space to the student, actively guide the student to think about how to design and complete the design. We divide students into project team. Project leader should have certain ability of organization and coordination ability, has the sense of responsibility, such as specific request, let the students democratically elected leader. Subject leader is the subject head. Project director should according to the design requirements, organize the collaborative design task group members. Then, the simulation to simulate the engineering design methods and steps of electronic technology course design.

\subsection{Scheme design and demonstration}

(1) The teachers design the topic. According to the goals of this course design, teachers put forward a number of different, the difficulty is roughly analog circuit design, practical subject of the 
performance of technical indicators, collective discussion by the subject leader organizing team members to choose design topic, and confirm the topic of group by a majority opinion of the design, and then, organize team members separately find relevant technical data, and requires each own put forward the preliminary design scheme.

(2) Design team argument. Project leader of the team members demonstrate design scheme, it is an important part of the teaching reform. All team members in the team project demonstration meeting to elaborate their overall design, and put forward amendments by team members to each other, play to team spirit, brainstorming, after full argument, put forward a whole group identity solutions in class.

(3) The class demonstration design scheme. Class scheme is under the teachers' group discussion meeting, each team elected representatives at the class scheme comparison in this paper, the design scheme, the design of the whole class for questions, asking questions, defend the group members, and then puts forward amendments. As a design scheme of project team, it must be designed after teachers' authorization.

At the end of this process, the project leader should organize the group members to give a mark according to the quality of each person to submit project, demonstration project argument sufficient degree, and the reasoning of the stand or fall of engagement and observe discipline, breakdown rate. The proportion were $50 \%, 30 \%, 50 \%$ and $30 \%$, respectively, to assess the excellent, good, medium, pass and fail in five, asked master cannot exceed $20 \%$, fail more than $5 \%$.This result will serve as the course design of the first phase of the result, $25 \%$ of the total grade. After several of the students on a trial basis, the students can be more objective to name the first four, etc. It has never been named failed pass the exam. The results are basically in agreement with such a score goals.

\subsection{Using the EDA technology to design the circuit simulation and PCB design.}

Electronic design automation (EDA) technology is the new technology of the current engineering design, the application of it makes the system analysis and design methods had a profound change, development and application of EDA technology has become a modern electronic engineering in the field of support technology, become the skill which the type of electricity and information engineering technical personnel must master. So, electronic information engineering, automation and other professional undergraduate college students during the period of school must learn and master it.

(1)The application of EWB circuit simulation to the design. In the design of analog electronic technology course, we try to put the focus on the EDA technology application training computer simulative and auxiliary design. After the students formulate preliminary scheme according to the design task, we must ask them to design the circuit on Electronics Workbench (EWB) simulation platform firstly. Students should analyzed the influence of the main circuit components parameters of index, static and dynamic performance, preliminary understanding circuit debugging circuit on the platform of EWB to technical indicators. To prepare for the adjustment of the circuit.

(2) Design printed circuit boards through Protel For Windows. After the EWB simulation, students are introduced to the printed circuit board design automation software Protel For Windows basic engineering knowledge and design of printed circuit boards, students are required to apply Protel For Windows each group to design the circuit principle diagram and software design drawing design printed circuit diagram. At the end of this process, teachers can score according to the situation about the students master the EDA technology and the ability to use EDA. This stage performance accounted for $25 \%$ of the final grade.

\subsection{Install and debug circuit}

(1) Install circuit. In the teaching reform of analog electronic technology course design, we will let the installation process of the circuit as to cultivate students' rigorous and realistic scientific attitude and earnest, steadfast work style. So, for students who get corrected installation will be added 5 points of a reward at a time; Deduct appropriate marks to students who have a lot of errors and rework several times. The students review the process of installing components detection technology again, improved the welding skills, and the use of common electronic instruments, meters. Thus, it not only 
make the installation of the circuit to be the process which students improve their basic skills, but also emphasizes the "rigorous scientific attitude, the steadfast work style is the guarantee of success" in the process.

(2) Debug the circuit. Debugging technique is one of the basic skills that IT industry engineers must master. The student's learning and training in debugging techniques is an important content of analog electronic technology course design, the content is under the guidance of teachers to complete the following steps: (1) requiring students to check installation lines in the case of no electricity according to the design circuit diagram;(2) with a pointer multimeter " $\Omega$ × 1" file, search for virtual welding, welding and other poor contact point;(3) debugging the unit circuit in the case of signals;(4) on the basis of debugging the unit circuit, expanding the scope of the debugging gradually, and finding out problems, modifying the circuit parameters, until fully meet the design requirements;5. After the debugging, comparing the measured circuit performance and computer simulation results, in order to meet the computer simulation's role in the circuit design. It makes the students' understanding of the EDA technology not only stay on the operation of the software system, but also have a whole understanding about the role of the technology in the electronic design, and can help cultivate their comprehensive ability. At the end of this phase, accounted for $35 \%$ of overall evaluation.

\subsection{Design reports.}

The reform is aimed at our school students' graduation design reports and the actual situation of the electronic design contest, our approach is as follows: (1) teachers explain the requirements of design report in 1 hours;(2)navigating previous students' good curriculum design report, and to give students a demonstration of written report;(3) to give students the proper time to write, set with two weeks after the report design course, so that let the students have plenty of time to think, write, and change the report. Accounting for $15 \%$ of the overall design report results.

\section{The effect and experience in the reform of analog electronic technology}

1) In the reform of the curriculum design, we emphasize the argumentation of the scheme and the design process of the implementation of this process, because of the independence of students are required to put forward the design scheme, design circuit and give full play to their independent thinking, independent analysis question, solve the problem of the subjective initiative, to improve the students' innovation ability, at the same time requirements in team discussion, modification, optimization design and make the students in the atmosphere of democracy and freedom are discussed. Knowledge and insights need to be inspired with each other, the problem and difficult need to be discussed, so in the discussion, a person's unique insights could open many people's eyes. And as a teacher, he or she should be in the process of his or her teaching for the students to create an environment and conditions can be discussed, encourage the students discuss freely around the topic, so as to inspire each other, complement each other, and the students can learn to exchanges and cooperation in this process, cultivate their team spirit.

2) In the reform of the curriculum design, we changed the traditional grading methods, adopted in stages, give evaluation to both the theory of design, and students' practice ability, engineering quality evaluation, it is more reasonable for evaluating with piecewise score. We also practice the student scored in democracy, which make the evaluation of the curriculum design's performance more open, fair and just. After grading the course design of three classes, students are very satisfied. The students think they are the master of curriculum design grading. Today, the curriculum design exams their new thinking and creativity, describes the ability to learn, checks their practice ability.

3) In the reform of the curriculum design, we adhere to take the student as the main body to improve the students' learning initiative, to cultivate the students' consciousness of rigorous earnest study style, work independently and engineering practice ability, improve their innovation consciousness and innovation ability. Students in curriculum design summary wrote: "I think the * practice 'is not only the exercise of the operational ability, but also of the global overall thought and 
coordination ability".

4) In the reform, we further recognize that practice is the most essential and the most important project of the properties of the higher engineering education to return to project, the first thing to strengthen practice, full attention guiding role of the practice teaching to cultivate the students' engineering ability. Thus, under the condition of our school to the analog electronic technology course design of teaching contents, teaching methods and means, we have carried on the preliminary research and practice of reform, outstanding student's main body status on the basis of the current curriculum design teaching, geared to the needs of engineering practice, updating experiment teaching content, teaching reform and practice environment, and it is explored how to improve the practice teaching quality and level. But it is a long and difficult road of teaching reform, teaching reform is the teacher's bounden duty, as an education worker, we should do our best.

\section{Acknowledgements}

Research on Provincial Teaching Reform in Hubei Province in 2016.

"Study on the school enterprise docking and integration of Electrical Engineering Specialty in local colleges and universities”, Project number:2016423.

\section{References}

[1] Wang Jian, Ye Xiaoyan, Shen Jianguo. The Teaching and Studying Practice of "Course Designing for Analog Electronics" [J]. J.Suzhou Institute of Urban Construction and Environmental Protection, 2002, 4(4):100-102.

[2] Wang Xiaoli, Zhou Xun, Xue Haiying. Research and practice on teaching reform in course design of Electronic Technology [J]. Experimental Technology and Management, 2014, v.31;No.214(7): 180-181.

[3] Lu Anshan. The Research and Develop on Multi-driver Based Analog Electronics Courses Reform [J]. Journal of Qinzhou University, 2012, 27(3):97-99.

[4] Zhu Bin, Tan Yong. Study and Practice on Course Reform of Electronic Technology [J]. Computer Knowledge and Technology, 2009, 5(5):1275-1276.

[5] Jiang Hong. The Reform Exploration for Teaching Mode of Analog Electronics Technique [J]. Journal of EEE, 2008, 30(3):4-5. 